\title{
Food security outcomes under a changing climate: impacts of mitigation and adaptation on vulnerability to food insecurity
}

\author{
Katy J. Richardson ${ }^{1}$ (D) Kirsty H. Lewis ${ }^{1}$. \\ P. Krishna Krishnamurthy ${ }^{2} \cdot$ Chris Kent $^{1}$ • \\ Andrew J. Wiltshire ${ }^{1} \cdot$ Helen M. Hanlon ${ }^{1}$
}

Received: 27 January 2017 / Accepted: 3 January 2018 / Published online: 3 February 2018

(C) The Author(s) 2018. This article is an open access publication

\begin{abstract}
Climate change is a potential threat to achieving food security, particularly in the most food insecure regions. However, interpreting climate change projections to better understand the potential impacts of a changing climate on food security outcomes is challenging. This paper addresses this challenge through presenting a framework that enables rapid country-level assessment of vulnerability to food insecurity under a range of climate change and adaptation investment scenarios. The results show that vulnerability to food insecurity is projected to increase under all emissions scenarios, and the geographic distribution of vulnerability is similar to that of the present-day; parts of sub-Saharan Africa and South Asia are most severely affected. High levels of adaptation act to off-set these increases; however, only the scenario with the highest level of mitigation combined with high levels of adaptation shows improvements in vulnerability compared to the present-day. The results highlight the dual requirement for mitigation and adaptation to avoid the worst impacts of climate change and to make gains in tackling food insecurity. The approach is an update to the existing Hunger and Climate Vulnerability Index methodology to enable future projections, and the framework presented allows rapid updates to the results as and when new information becomes available, such as updated country-level yield data or climate model output. This approach provides a framework for assessing policy-relevant human food security outcomes for use in long-term climate change and food security planning; the results have been made available on an interactive website for policymakers (www.metoffice.gov.uk/food-insecurity-index).
\end{abstract}

Electronic supplementary material The online version of this article (https://doi.org/10.1007/s10584-0182137-y) contains supplementary material, which is available to authorized users.

Katy J. Richardson

Katy.richardson@metoffice.gov.uk

1 Met Office Hadley Centre, Fitzroy Road, Exeter EX1 3PB, UK

2 World Food Programme, Regional Bureau for Asia, 55 Wireless Road, Wave Place Building, 7th floor, Bangkok 10300, Thailand 
Keywords Vulnerability index · Climate change · Food security · Mitigation · Adaptation .

Climate risk management $\cdot$ Climate projections

\section{Introduction}

Around 815 million people worldwide are chronically undernourished (FAO et al. 2017). The 2030 Agenda for Sustainable Development aims to end hunger and achieve food security (Sustainable Development Goal 2; UNDP 2015); however, achieving this in the face of a changing climate will require increased investments and planning. Therefore, there is an urgent requirement for easily accessible, policy-relevant information about the impacts of climate change on food security, to ensure decision makers are equipped with useful and practical advice to inform long-term planning (Lobell et al. 2008; Brown and Funk 2008; Gornall et al. 2010; Foresight 2011; Wheeler and von Braun 2013; Porter et al. 2014; Vermeulen 2014). Such information needs to address questions on the direction and scale of change, and the timing and location of the worst impacts, in order to support prioritisation of mitigation and adaptation solutions.

Most studies investigating the relationship between climate change and food security have been limited to specific aspects which include impacts on food availability focusing on crop production (Parry et al. 2004; Lobell et al. 2008; Liu et al. 2013; Kurukulasuriya and Rosenthal 2013; Porter et al. 2014), impacts on access focusing on food prices (Nelson et al. 2010; Lobell et al. 2011) and impacts on utilisation focusing on nutrition outcomes (Thompson and Cohen 2012). However, few studies take a more holistic view and translate this information into policy-relevant human food security outcomes.

The Hunger and Climate Vulnerability Index (HCVI; Krishnamurthy et al. 2014) was developed as a novel approach to address this knowledge gap. The index provides a country-level assessment of vulnerability to food insecurity as a result of climate events by combining information about exposure to present-day climate hazards (such as floods, droughts and storms) and food security relevant measures of sensitivity and adaptive capacity (more detail is provided in Section 2). However, the HCVI does not assess how vulnerability could change under future climate change. This paper builds on the HCVI and adapts the method to enable incorporation of climate model projections under different emissions scenarios. In addition, the paper highlights an approach to incorporate scenarios of food system investment. Food system investment means improvements to all aspects of food security, which includes improvements to agricultural production, market function and national infrastructure, for example. This could be considered an outcome of economic growth, and this is reflected in the elements of the index. For brevity, these scenarios of food system investment are referred to as the general term 'adaptation' throughout this paper.

The revised index presented here provides quantification, at a global level, of the scale and direction of impact of climate change on food insecurity in developing and least-developed countries (through projected changes in metrics of flood and drought events). As such, it aims to provide information to help policymakers understand the level of challenge to global food security that climate change presents, provide information on the geography of the impacts, and help to evaluate the relative benefits of mitigation and adaptation responses. The index is not a detailed planning tool, but aims to support prioritisation of effort and to help planners evaluate the nature of the top-level threat to food insecurity that climate change presents. 
The challenge in developing this index was to take climate model output and to translate it into food security outcomes of most relevance to high-level decision makers. Although the index is driven by climate data, it does not present these data directly. This is important because it means that policymakers are not required to try to interpret the climate science themselves. The index was developed through collaboration between climate science and food security expertise, and so expert judgement was available to be applied to the interpretation, in order to minimise misuse of either types of information. Interdisciplinary research between natural and social science disciplines faces a number of challenges (Lewis and Lenton 2015); this index is an example where these disciplinary boundaries have been bridged, to provide integrated evidence on the human outcomes of climate change.

\section{Method}

This paper presents a method for calculating future projections of the experimental Hunger and Climate Vulnerability Index (HCVI), originally presented in Krishnamurthy et al. (2014). The HCVI is a scaled country-level index which provides a relative measure of vulnerability to food insecurity (referred to as VFI from here on) as a result of climate-related hazards.

Vulnerability, as measured by the HCVI, is the result of the interaction between three components:

- Exposure to climate-related hazards,

- Sensitivity of national agricultural production to climate-related hazards,

- Adaptive capacity - a measure of capacity to cope with climate-related food shocks.

Each of these components comprises a number of country-level indicators which were selected based on availability of the data at the national level, their relevance to food security and their correlation with undernutrition (FAO 2014; indicators are listed in Fig. 1a; also see Krishnamurthy et al. (2014) for rationale for the selected indicators). Calculation of the HCVI assumes that each component contributes equally to vulnerability, regardless of the number of indicators within each component (c.f. Sullivan 2002; Harn et al. 2009).

Even though the existing HCVI contains measures of climate hazards, these indicators are not derived from meteorological data; they come from self-reported disaster information (EM-DAT ${ }^{1}$ ). Therefore, in order to calculate future projections of the HCVI with climate model projections, the HCVI methodology had to first be updated to enable the use of gridded climate data to provide a baseline measure with which to compare the future changes.

\subsection{Present-day vulnerability to food insecurity: updates to the HCVI}

Two main updates to the HCVI methodology were made; firstly, OECD and EU countries were excluded from this iteration of the index, and secondly, the exposure component was replaced with an indicator derived from gridded climate data. All other methods and indicators utilised in the HCVI remain unchanged to those presented in Krishnamurthy et al. (2014). A schematic of the revised index calculation is provided in Fig. $1 \mathrm{~b}$.

${ }^{1}$ EM-DAT - The International Disaster Database (http://emdat.be/). 


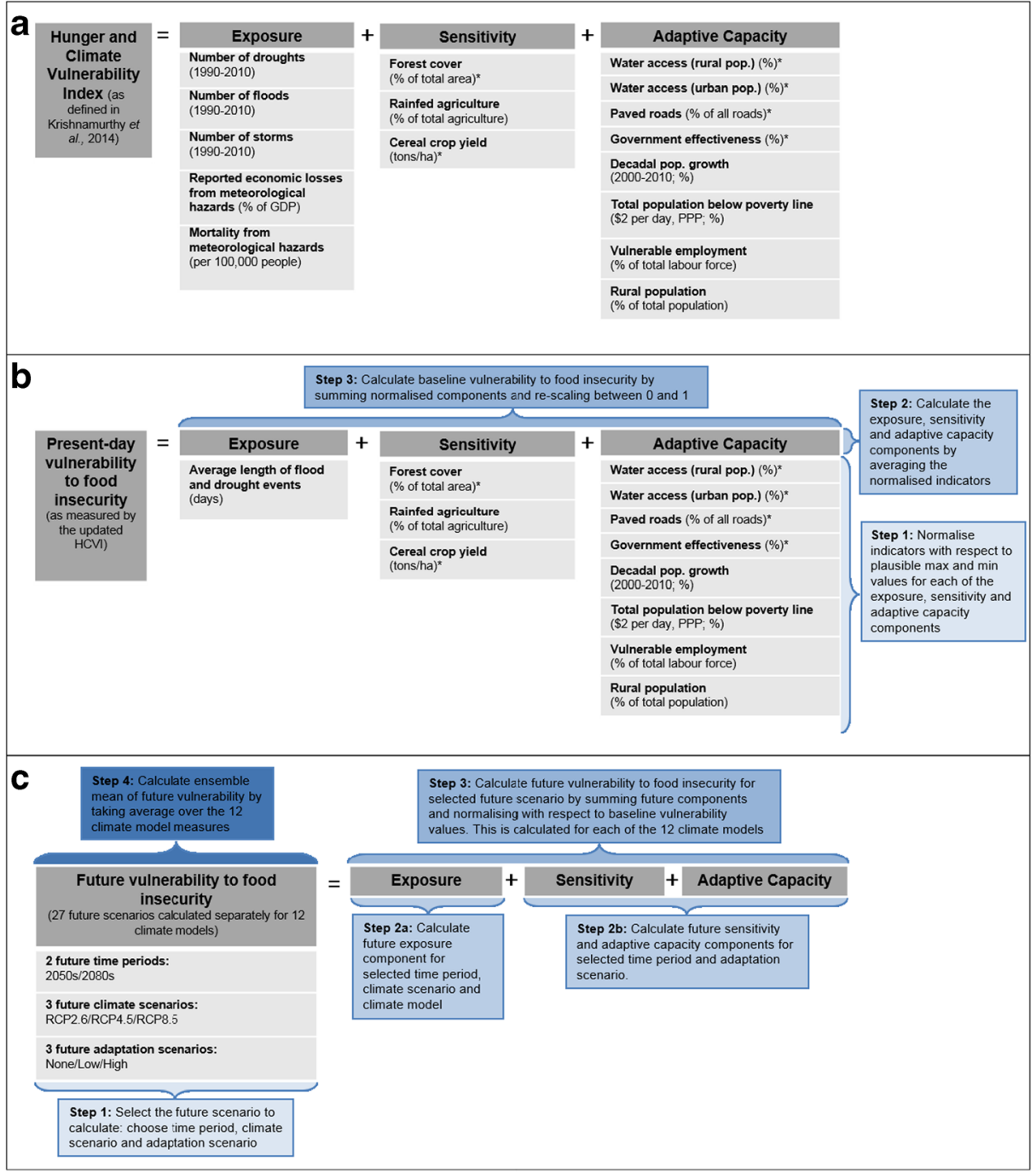

Fig. 1 Schematic of the original and updated HCVI calculation. a Indicators used in the original HCVI from Krishnamurthy et al. (2014); data sources are provided in Section SM1. b Calculation of present-day VFI as measured with the updated HCVI which uses climate data over the 1981-2010 baseline period to derive the exposure component (method described in Section 2.1). c Process of computing the ensemble mean of future VFI under the 18 future scenarios considered (two time periods, three emissions scenarios and three adaptation scenarios)

\subsubsection{Excluding OECD and EU countries}

A review of the HCVI methodology resulted in exclusion of OECD and EU countries in this revised version of the index. This is because access to markets and economic interconnectedness in the most developed countries means their food systems operate differently from those in developing countries. Further updates to the HCVI to account for agricultural trade are required to be able to include these countries. 
As a result of this exclusion, the normalisation process applied to the country-level indicators used to calculate the sensitivity and adaptive capacity components was updated. In this revised iteration, the indicator values are normalised with respect to physically plausible maximum and minimum values as opposed to the maximum and minimum across the available data. This resulted in sensitivity and adaptive capacity components which are both measured on a normalised zero-to-one scale, relative to physically plausible limits. For adaptive capacity, zero represents the highest value of adaptive capacity the individual indicators could give, and the value of one represents the lowest. Conversely, for sensitivity, zero represents the lowest value and one represents the highest. This ensured that when the scenarios of adaptation investment were applied to the future projections of VFI the results were constrained by feasible limits (see Section 2.2.2 and Section SM1 for further detail).

\subsubsection{Updating the exposure component to use gridded climate data}

Updating the HCVI to use gridded climate data required replacement of the climate relevant indicators, where possible, with indicators assessed with gridded climate data. The aim was to replicate the original HCVI as best as possible to ensure qualitative comparison of the results.

All five indicators in the exposure component of the original HCVI were related to climate (Fig. 1a); however, not all of them could be reproduced from climate model output. The indicators representing economic losses and mortality due to meteorological hazards are also partially driven by socio-economic factors and are therefore not possible to recreate from analysis of climate data. As it would be inconsistent to keep these indicators constant while considering the projected changes in climate hazards, both were excluded from this revised HCVI.

Constructing the remaining exposure indicators with gridded climate data was challenging; only variables available from global climate models (GCMs) and at the temporal and spatial scales of GCMs could be used so that similar measures could be calculated with the climate model projections. In addition, indictors were required to correlate with undernutrition (FAO 2014) at the national level to meet the criteria for inclusion in the HCVI.

Data from the WFDEI meteorological forcing dataset (Weedon et al. 2014) for the baseline period of 1981-2010 were used to construct baseline measures of exposure to climate hazards. Only indicators of flood and drought events were considered as it was not possible to construct a meaningful indicator of storm events due to resolution restrictions. ${ }^{2}$

Since GCMs do not output flood and drought information, suitable proxies for flood and drought events that best reflect the potential changes in flooding and drought were developed using daily precipitation data. These were measures of excess precipitation and precipitation deficit respectively, relative to the climatology, using adaptations of the Moving Average Precipitation Variable Threshold (MAPVT) indicator (Wanders et al. 2010; further detail is provided in Section SM2).

Country-level indicators of flood and drought events were constructed by selecting the median value within a country's border. After excluding OECD and EU countries, and also countries less than $500 \mathrm{~km}^{2}$ as they are not adequately resolved within the low resolution grids of GCMs, correlations with undernutrition were not found. This is not surprising given that the

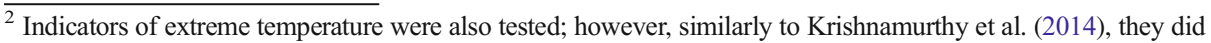
not correlate with undernutrition.
} 
indicators constructed with objective information from climate reanalysis do not exactly replicate the subjective self-reported information used in the original HCVI.

To account for 'exposure' to the hazards (as opposed to instances of the hazards), the flood and drought proxies were masked to only include regions where a significant proportion of people live ${ }^{3}$, and with more than $1 \%$ of the grid cell given over to crop production. ${ }^{4}$ Countries with no grid cells after applying the mask, such as Libya and Saudi Arabia (see Fig. SM2.1), have no exposure component and were therefore excluded from the index calculation. This is justified as the index assumes in-country production and consumption of food and the food systems in these countries where the mask criteria are not met are mostly dependent on imported food. The food security of these countries is therefore dependent on climaterelated hazards in the regions where their imported food is produced; however, this consideration is out of scope of the index calculation.

Application of the mask improved the correlation scores. An indicator that combined the average length metrics of the flood and drought events proxies scored the best correlation with undernutrition and was therefore used to replace the exposure component in the HCVI calculation (Fig. 1b). The exposure values or reasons for exclusion for each country are provided in Section SM3.

\subsection{Calculating future projections of vulnerability to food insecurity}

The revised HCVI methodology results in an updated measure of the present-day VFI, which utilises gridded climate data in an approach compatible with climate model output. Future projections of VFI as a result of projected changes in climate are calculated by assessing the exposure component of the revised HCVI with daily precipitation data from climate model projections for a range of emissions scenarios and future time periods (see Section 2.2.1 for detail $)^{5}$. In addition, scenarios of adaptation investment that change the sensitivity and adaptive capacity components of the index were developed and applied (see Section 2.2.2 for detail). Future VFI was assessed using the same method as the present-day by combining the future measures of exposure, sensitivity and adaptive capacity with equal weighting; however, all values were normalised to the present-day measures in order to give context to the projected values (as shown in Fig. 1c). Future VFI values over one represent VFI levels greater than any seen in the present-day, and values were capped at 1.5 as values over this threshold were outliers of the distribution.

\subsubsection{Calculating future projections of exposure under different emissions scenarios}

Future projections of the exposure component of the index were calculated using daily precipitation data from a subset of 12 GCMs from the CMIP5 multi-model ensemble (Taylor et al. 2012), used to inform the Intergovernmental Panel on Climate Change Fifth Assessment Report (IPCC AR5; IPCC 2013). The future projections were calculated for three

\footnotetext{
${ }^{3}$ Population density greater than 150 people per $\mathrm{km}^{2}$ as areas with fewer people per $\mathrm{km}^{2}$ are considered to be rural as per OECD (2011), using an estimate of population density in the year 2000 (van Vuuren et al. 2007)

${ }_{5}^{4}$ Using cropland data representative of the year 2000 from Monfreda et al. (2008)

${ }^{5}$ It is noted that in this method the projected changes in climate are only considered as part of the exposure component, and that the impacts of climate on crop yield (in the sensitivity component) are not considered here. Information on an initial test to consider changes in Net Primary Productivity as a proxy for crop yield is provided in Section SM4.
} 
concentration driven emissions scenarios; RCP2.6, RCP4.5 and RCP8.5 (van Vuuren et al. 2011a), for two future time periods; the 2050s (2041-2070) and the 2080s (2071-2100). For each climate model, the average length of flood and drought events indicator was calculated following the method in Section 2.1.2 for both the baseline and future time periods. The future measure was normalised with respect to the relevant baseline values, and the model anomalies added to the baseline exposure values as calculated with the WFDEI reanalysis data. Further detail about the climate models and limitations of the future projections of exposure is provided in Section SM4.

\subsubsection{Calculating scenarios of adaptation investment}

Whilst it is possible to systematically sample a range of plausible future changes in climate under different emissions scenarios through the use of GCMs, this only enables understanding of changes in the climate-related exposure component of the index, without considering the socio-economic elements of VFI. Understanding the isolated impacts of climate change on VFI is a useful task; however, it is not reasonable to assume that a country's sensitivity or adaptive capacity will not change in the future. Projecting future changes in these aspects is extremely difficult as they are dependent on many variables.

In order to address this, and to provide a sense of the relative scale of change associated with changes in the sensitivity and adaptive capacity components of the index, relative to the climate changes to the exposure component, two scenarios of adaptation were developed. These were low and high 'adaptation', with a third scenario option of no 'adaptation'. The no adaptation scenario maintains the sensitivity and adaptive capacity components at the presentday level, resulting in future projections of VFI as a result of projected changes in climate only.

The low and high adaptation scenarios represent reductions in how sensitive agricultural production is to climate-related hazards, and increases in capacity to cope with climate-related food shocks, through changing the sensitivity and adaptive capacity components of the index accordingly (not the individual indicators that make up these components). Predicting socioeconomic changes, particularly for individual indicators is impossible and would result in additional uncertainty and conditionality of the index, which would undermine its utility. Adjusting the components of the index in line with the Shared Socio-economic Pathways (SSPs; O'Neill et al. 2014) was also unfeasible, mainly because the SSPs do not contain all the information required on the individual indicators. Developing scenarios which apply a standardised change to the sensitivity and adaptive capacity components as a whole was deemed the most useful and practical approach, but determining the appropriate levels of change to apply for each scenario is critical.

The countries included in the index mostly have low adaptive capacity and high sensitivity on the normalised zero-to-one scales. The scenario for high adaptation was therefore designed to be one where the majority of the countries in the index moved to have improved adaptive capacity and sensitivity values closer to those seen in developed countries, and near the maximum that could plausibly be achieved. The low adaptation scenario was then set to result in improvement halfway between no change and high adaptation.

The changes actually applied were scaled using a logarithmic function which was dependent on the present-day measures of sensitivity and adaptive capacity. This allowed countries that had relatively high measures of sensitivity or poor adaptive capacity in the present-day to improve more readily than those with lower present-day measures, for the same level of investment. The rationale for this was that the most sensitive countries with the lowest levels of 
adaptive capacity in the present-day could benefit from investments in adaptation, but it becomes increasingly difficult to make gains for countries starting from a more advanced point. The scaled changes result in reductions in sensitivity or improvements in adaptive capacity that range from around 10 to around $15 \%$ in the high adaptation scenario, and similar changes of around 5 to around $10 \%$ in the low adaptation scenario. The change was applied to the present-day values for the 2050s time period, and the same change was then applied to the 2050 s values for the 2080 s time period. Any resulting negative values were set to zero as this was deemed to be the lowest plausible value based on the physically plausible limits used for the normalisation in the present-day. Further detail on the method applied is given in Section SM5, including histograms that illustrate the level of change applied (Fig. SM5.1).

The resulting scenarios do not contain any information on how easy it may be to achieve the levels of improvement shown, but they do give information about what could be achieved if there were concerted investments to address the higher sensitivity and lower adaptive capacity in developing and least-developed countries, that brought them closer to the optimal values and those seen in developed countries. This sense of the scale of change possible in the non-climate factors is then a useful comparison with the climate change impacts, to give a much clearer sense of the scale of the challenge climate change presents.

\section{Results and discussion}

\subsection{Present-day vulnerability to food insecurity}

VFI for the baseline period (1981-2010) was calculated following the updated and adapted HCVI methodology presented in Section 2.1 and Fig. 1b and is mapped in Fig. 2a along with a histogram showing the distribution of the index and individual component values (Fig. 2b). The highest levels of VFI are found in Sub-Saharan Africa, with medium levels across much of Asia, and lower levels in South and Central America. This pattern is consistent with the results from the original HCVI (Krishnamurthy et al. 2014) and measures of undernutrition and food insecurity (FAO 2014), reiterating that climate vulnerability and food insecurity are closely interlinked.

Maps and histograms of the exposure, sensitivity and adaptive capacity components of the present-day index are also shown in Fig. 2. The geographic pattern of each of the components is similar to that of the overall index with the largest values in Sub-Saharan Africa. A table of the index and individual component values is provided in Section SM3.

\subsection{Future projections of vulnerability to food insecurity}

Future VFI was calculated following the methodology presented in Section 2.2 and Fig. 1c. Maps of the future VFI values for the extreme range of the scenarios considered are shown in Fig. 3; these are the lowest and highest emissions pathways (RCP2.6 and RCP8.5) with both no and high adaptation for the 2050s and 2080s. Anomalies from the present-day of the results shown in Fig. 3 are mapped in Fig. 4, and the isolated effects of mitigation and adaptation on VFI are mapped in Fig. 5.

The results presented here are the ensemble mean of the VFI results. The model ensemble exhibits a range of results across the models due to the range of projected changes in precipitation across the models; however, the ensemble mean is indicative 

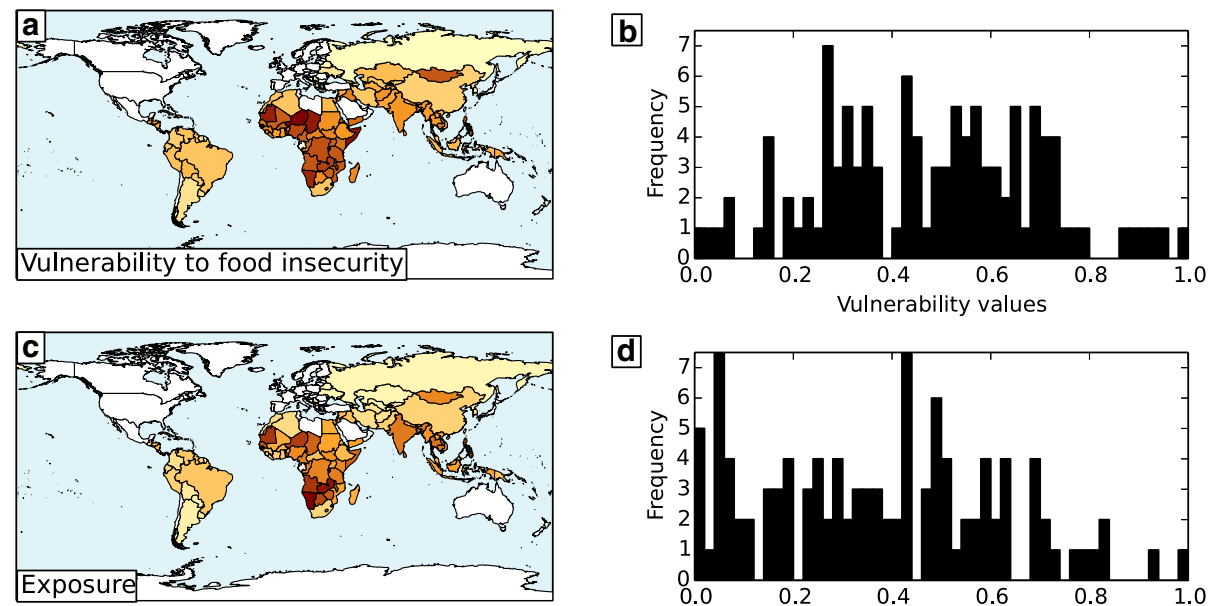

d
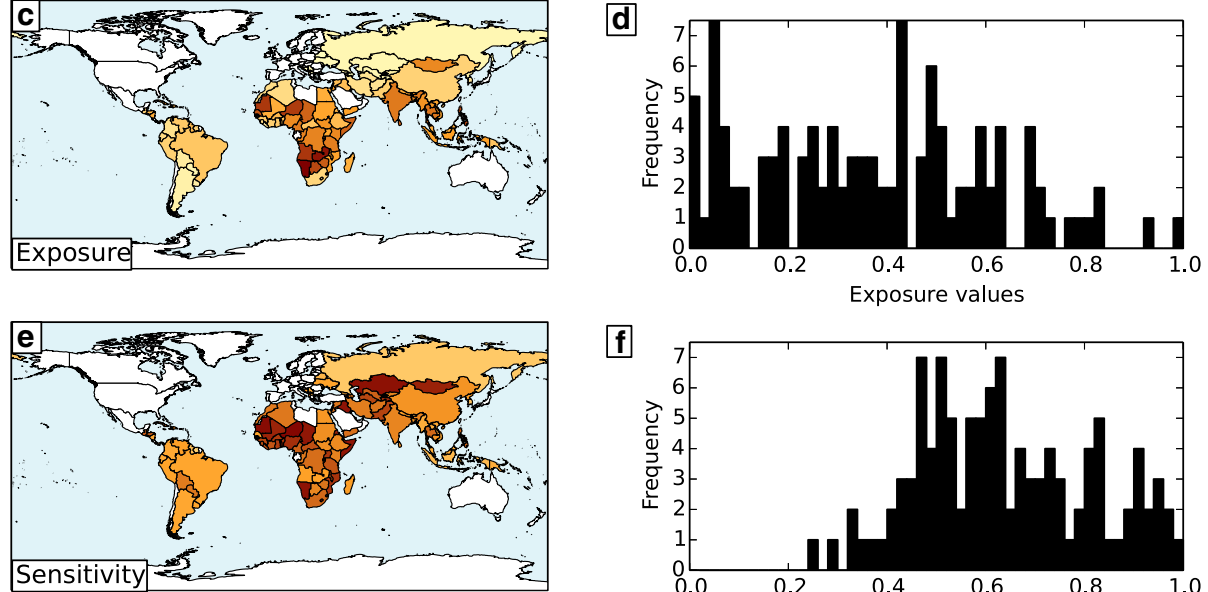

$\mathbf{f}$
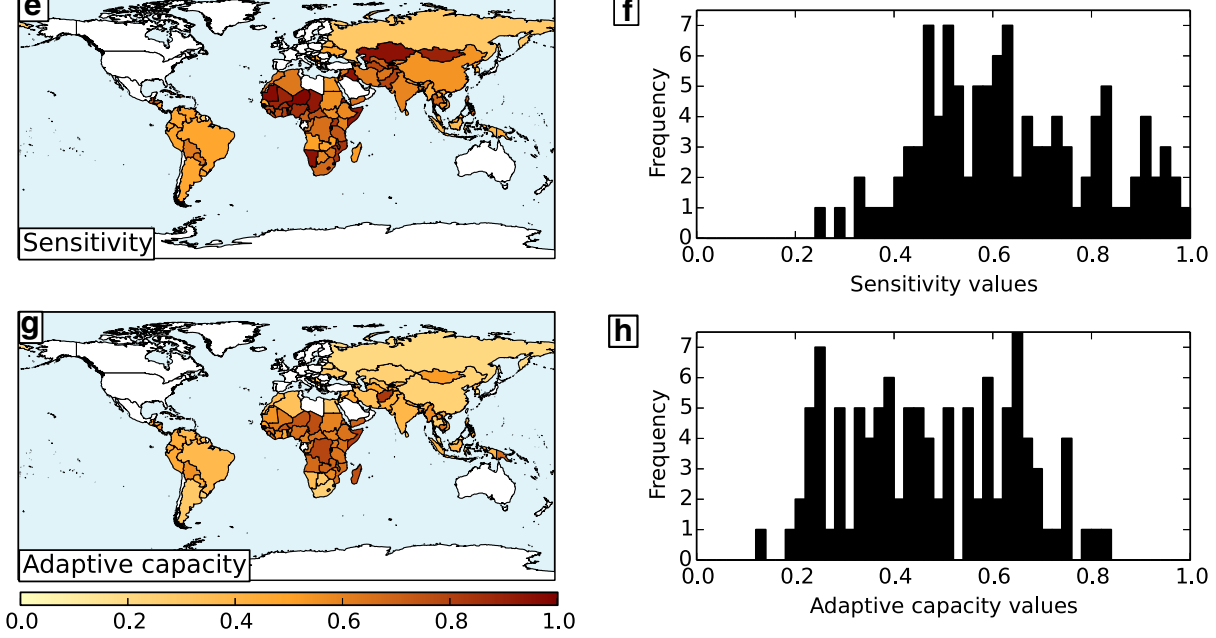

h

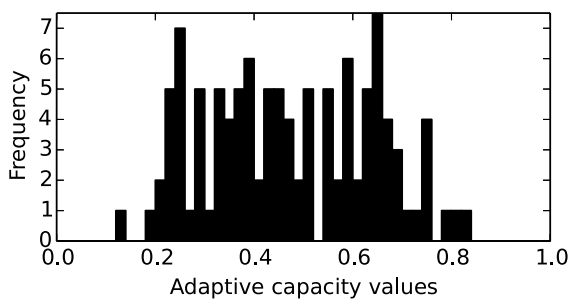

Fig. 2 Maps and histograms of the baseline VFI (a, b) and individual components: exposure (c, d), sensitivity (e, f) and adaptive capacity $(\mathbf{g}, \mathbf{h})$. Note that the adaptive capacity component plotted here is the inverted measure as this is the way it contributes to the index

of the spatial pattern across each of the individual models. One key limitation with the use of the ensemble mean is that known issues with climate model projections in West Africa result in relatively smaller changes in the ensemble mean value than for the rest of the region; further detail and other limitations of the results are discussed in Section SM4. Anomalies for the full set of results, including the spread across the climate models and ensemble statistics, are shown in Section SM6. A website visualising the index for all scenario combinations was also created and is available at: www.metoffice.gov.uk/food-insecurity-index.

By the 2050s (left panels of Figs. 3 and 4), VFI increases compared to the presentday in all countries under all emissions scenarios in the absence of adaptation (anomalies from the present-day are all positive; Fig. 4c, g). These increases in VFI are as a result of projected changes in the average length of the flood and drought 

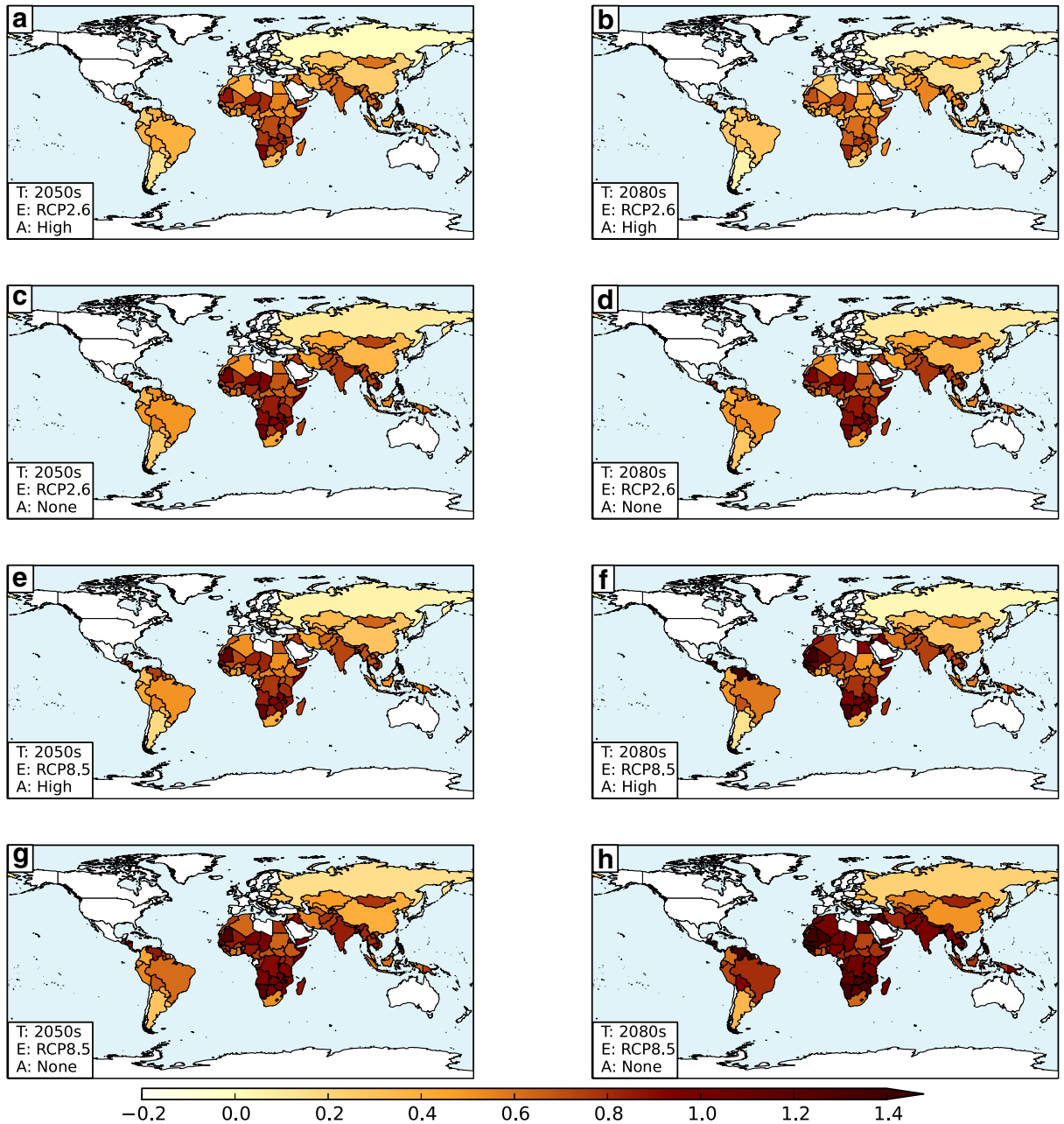

Fig. 3 Future VFI for a range of future time periods (T; left panels (a, c, e, g) show the 2050s and the right panels (b, d, f, h) show the 2080s), emissions scenarios (E; top two rows (a-d) show RCP2.6 and the bottom two rows (e-h) show RCP8.5), and scenarios of adaptation investment (A; panels $\mathbf{a}, \mathbf{b}, \mathbf{e}$ and $\mathbf{f}$ show high adaptation and panels $\mathbf{c}, \mathbf{d}, \mathbf{g}$ and $\mathbf{h}$ show no adaptation)

event proxies, using daily precipitation from the climate model projections. The geographic distribution of VFI is similar to the present-day, with some countries more vulnerable than the present-day (values $>1$ ). Increases under RCP8.5 are larger than those under RCP2.6 as larger changes in climate are projected in this emission pathway (Fig. 5a). However, much of this increase in VFI can be off-set by a high level of adaptation investment (e panels), particularly under RCP2.6 where VFI levels are similar to the present-day values (a panels).

By the 2080s (right panels of Figs. 3 and 4), the patterns of VFI diverge dramatically between the two emissions scenarios (Figs. 3d, h; 4d, h). For RCP2.6, there is little change between levels of VFI in the 2050s and 2080s when no adaptation to climate change is considered (compare panels c and d of Figs. 3 and 4). This is due to the rapid and sustained 

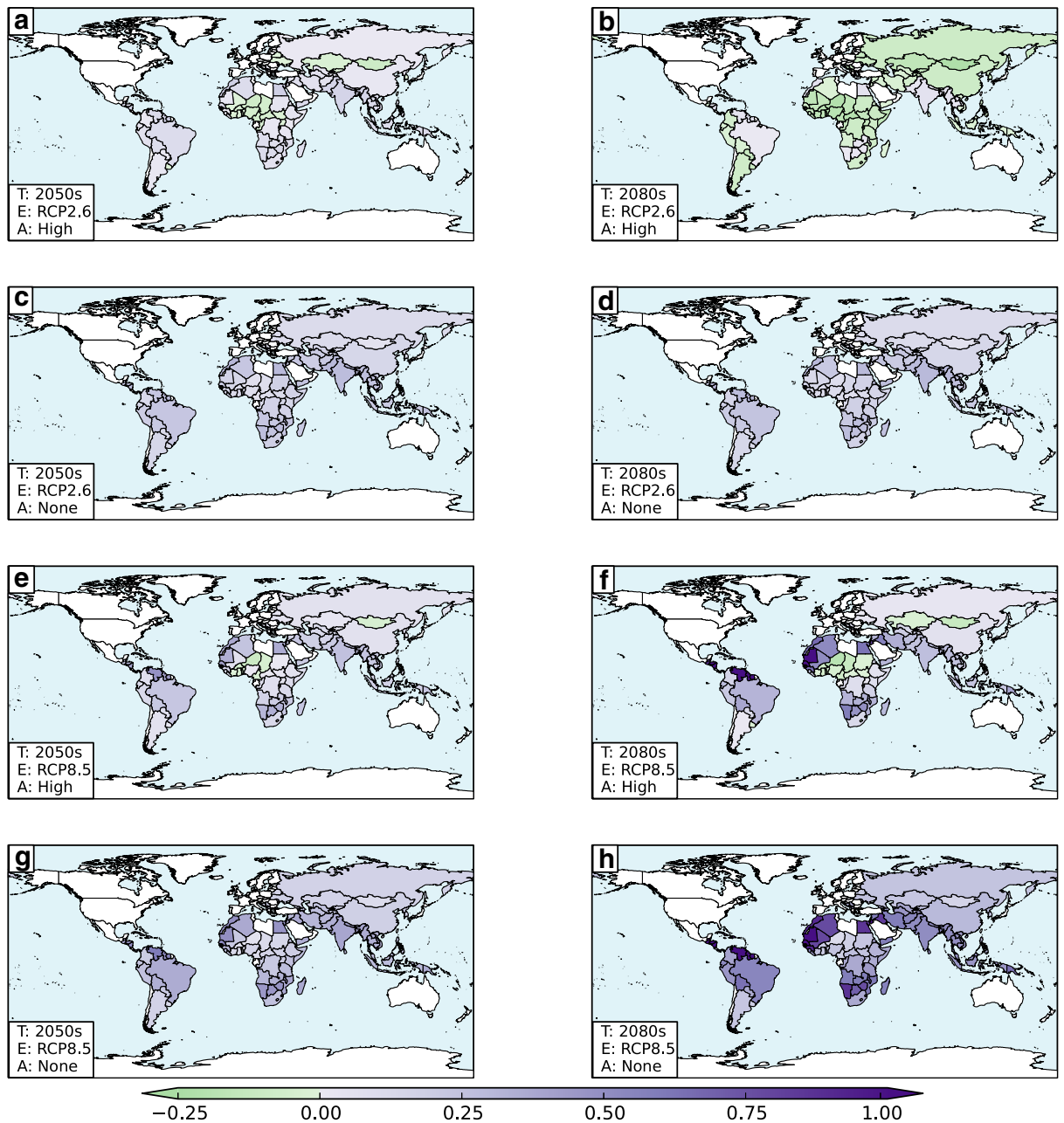

Fig. 4 Projected change in VFI; anomalies between panels in Fig. 3 and the present-day (Fig. 2a)

reduction in emissions represented by this pathway, resulting in a stabilisation of the climate after the 2050s. In contrast, considerable increases in emissions in the RCP8.5 scenario result in larger changes in precipitation, which in turn result in continued increases in VFI in the absence of adaptation. The largest increases are projected across West and Southern Africa, parts of South Asia, and Central and northern South America (Fig. 4f; Fig. 5b). This geographic distribution of VFI is similar to the present-day, with the largest projected increases occurring in areas that currently experience the greatest VFI (Fig. 2a).

Investment in adaptation acts to reduce the effects of climate change on the VFI values through reducing sensitivity to climate-related shocks and improving adaptive capacity (Fig. $5 \mathrm{c}, \mathrm{d}$ ) via the scaled adaptation scenarios (Section 2.2.2). A high level of adaptation investment limits the increase in VFI in both emission scenarios. However, under the high emissions scenario, RCP8.5, even high levels of adaptation investment are not sufficient to counteract the effects of climate change, resulting in increased VFI compared to the 2050s and the present-day in 

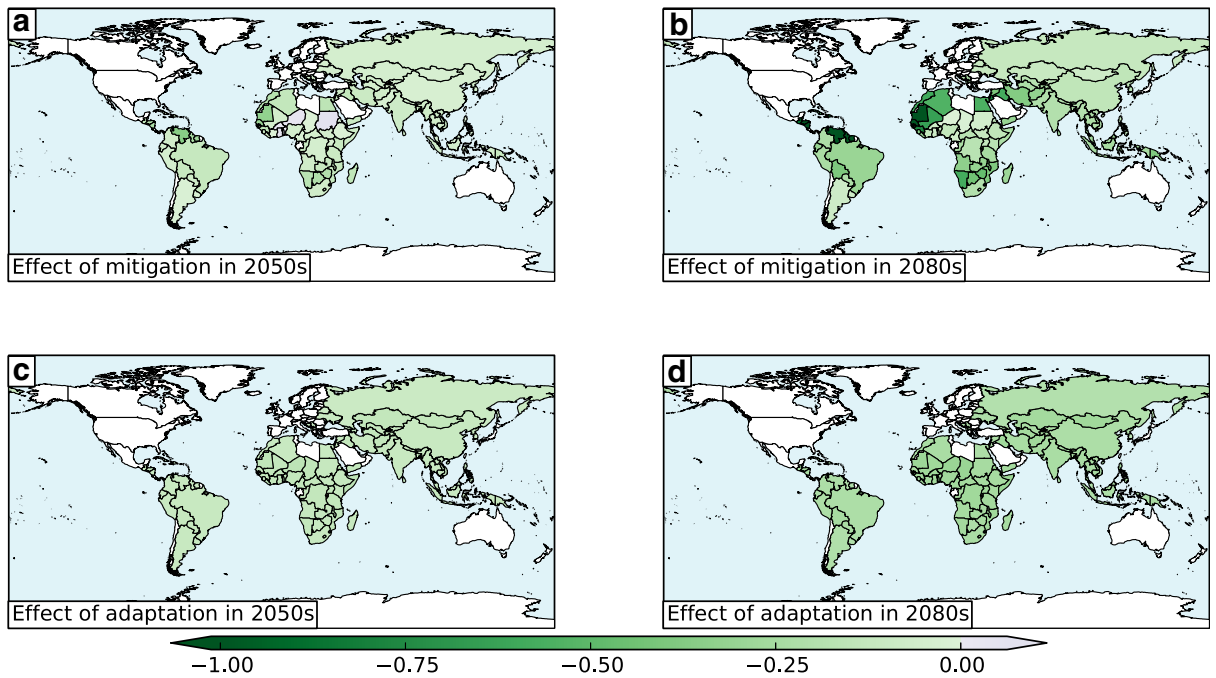

Fig. 5 Maps of the effect of mitigation and adaptation investment on VFI in the 2050s and 2080s. a, b Differences between the high and low emissions scenarios with no adaptation in the 2050s (Fig. 3g - Fig. 3c) and the 2080s (Fig. 3h - Fig. 3d) respectively. c, d Differences between the high and no adaptation scenarios with the low emissions scenario in the 2050s (Fig. 3c - Fig. 3a) and the 2080s (Fig. 3d - Fig. 3b). Note that the effect of adaptation is the same for all emissions scenarios due to the nature of the index

most countries (Fig. 4e, f). This contrasts to the lower emissions scenario, RCP2.6, where the effects of adaptation investment reduce VFI compared to the 2050s and also compared to the present-day in most countries (Fig. 4a, b). This scenario, with the most ambitious emissions scenario $^{6}$ and highest level of adaptation, is the only scenario of all 18 scenarios considered which shows reduced VFI compared to the present-day in the majority of countries, highlighting the requirement for both mitigation and adaptation in order to improve current levels of food insecurity.

\section{Conclusions}

This paper presents a method for assessing the complex relationship between climate change and food security through an index measure of comparative vulnerability to food insecurity (VFI) in developing and least-developed countries. It provides a framework for rapid translation of climate information into food security outcomes at a national level, to assist with longterm planning. The index demonstrates the scale and direction of change associated with climate change on food insecurity, both under mitigation and adaptation scenarios. This allows policymakers to understand something of the geography of future food insecurity, and prioritise accordingly, and to evaluate the relative benefits of both adaptation and mitigation

\footnotetext{
${ }^{6}$ Note that the RCP2.6 scenario assumes that some proportion of agricultural land is given over to biofuels (Tilman et al. 2009) to meet bio-energy requirements for climate mitigation (van Vuuren et al. 2011b). This reduces the land available for food production, which could negatively impact on food security. This is not accounted for in this index, which only includes the direct impacts of changing weather conditions on VFI. Land use changes were excluded because the actual distribution of these changes required to meet the biofuel commitments in this scenario is not specified. This means the projection of the index under RCP2.6 is an optimistic one, but not necessarily unrealistic, if it is assumed that the highest yielding countries, with higher baseline food security status, would undertake the majority of the biofuel production.
} 
action. The index does not provide detail on how VFI may develop at a sub-national level, and is not predictive, but does provide a view of what climate change projections mean when interpreted from a food insecurity perspective.

The existing Hunger and Climate Vulnerability Index methodology from Krishnamurthy et al. (2014) was updated to incorporate the use of gridded climate data, and the revised index utilised to assess the present-day VFI. Future projections of the revised index for the 2050s and 2080s were calculated using daily precipitation data from climate model outputs under different emissions pathways to illustrate how a changing climate could exacerbate existing food insecurity. In addition, standardised scenarios of adaptation investment which represent improvements to all aspects of the food system were applied to illustrate the benefits adaptation could bring.

One key benefit of using this vulnerability index approach driven by GCM projections is that it is a means to translate the GCM data into food security outcomes. Thereby showing the impact of a changing climate on a measure of VFI, and not just the climate changes themselves, which may be of less value for a food security planner. Secondly, the index allows comparison, in terms of outcomes, of the effect of investment in mitigation and in adaptation.

The results show that climate change increases existing VFI in all countries under all emissions scenarios. By the end of the twenty-first century, the impacts of mitigating climate change are apparent: little change in VFI is projected under RCP2.6, whereas the accelerated change in climate projected under RCP8.5 results in severe levels of VFI, particularly in countries which are already most vulnerable.

The analysis indicates that investment in adaptation results in lower VFI; however, adaptation alone is not sufficient to off-set all the impacts of un-mitigated climate change. The only future projection to show reductions in VFI, by the end of the twenty-first century compared to the present-day, is the scenario with both the highest level of adaptation investment and the highest level of climate change mitigation (RCP2.6).

These results suggest that climate drivers will exacerbate food security risks and that, in the absence of sufficient mitigation and adaptation, we may need to consider a shift in expected climate-related risks and vulnerability. The results therefore highlight the importance of a twintrack approach including mitigation and adaptation to ensure future food security and are available as an interactive web tool to provide evidence for policymakers in long-term planning.

Here, it is important to recognise that non-climate factors - such as food price volatility, conflict and market interconnectedness - ultimately also influence how vulnerable a population's food security status is. National development will likely improve countries' food security, independently of climate change adaptation activities. Ultimately, the index presented here should be interpreted in a broader context as one tool to help inform climate change and food security planning, which can be complemented by other models.

Acknowledgements The authors acknowledge funding from the UK Ministry of Defence's Development, Concepts and Doctrine Centre (DCDC), funding from the Government of Sweden's fast-track climate finance under the C-ADAPT project and funding from the Directorate for Development Cooperation of the Luxembourg Ministry of Foreign Affairs and the Norwegian Ministry of Foreign Affairs to carry out the work to develop the paper.

We acknowledge the World Climate Research Programme's Working Group on Coupled Modelling, which is responsible for CMIP, and we thank the climate modelling groups (listed in Table SM4.1) for producing and making available their model output. For CMIP the U.S. Department of Energy's Program for Climate Model Diagnosis and Intercomparison provides coordinating support and led development of software infrastructure in 
partnership with the Global Organisation for Earth System Science Portals. We thank Jamie Kettleborough, Ian Edmond, and Emma Hibling for developing the software used to download CMIP5 data. We also thank Pete Falloon, Richard Betts and Edward Pope for discussion and insightful comments on earlier drafts of this paper.

Open Access This article is distributed under the terms of the Creative Commons Attribution 4.0 International License (http://creativecommons.org/licenses/by/4.0/), which permits unrestricted use, distribution, and reproduction in any medium, provided you give appropriate credit to the original author(s) and the source, provide a link to the Creative Commons license, and indicate if changes were made.

\section{References}

Brown, M.E. and Funk, C.C. (2008) Food security under climate change. NASA Publication. Paper 131. Available online at: http://digitalcommons.unl.edu/nasapub/131

FAO (2014) Food security indicators. Available online at: http://www.fao.org/economic/ess/ess-fs/essfadata/en/\#.VCKpjed_qjQ, accessed in December 2013

FAO, IFAD and WFP (2017) The state of food insecurity in the world 2017. Rome, FAO

Foresight (2011) The future of food and farming: final project report. The Government Office for Science, London

Gornall J, Betts R, Burke E, Clark R, Camp J, Willett K, Wiltshire A (2010) Implications of climate change for agricultural productivity in the early twenty-first century. Philosophical Transactions Royal Soc London B: Biological Sci 365(1554):2973-2989. https://doi.org/10.1098/rstb.2010.0158

Hahn MB, Riederer AM, Foster SO (2009) The livelihood vulnerability index: a pragmatic approach to assessing risks from climate variability and change — a case study in Mozambique. Glob Environ Chang 19:74-88

IPCC (2013) Climate Change 2013: The Physical Science Basis. Contribution of Working Group I to the Fifth Assessment Report of the Intergovernmental Panel on Climate Change [Stocker, T.F., D. Qin, G.-K. Plattner, M. Tignor, S.K. Allen, J. Boschung, A. Nauels, Y. Xia, V. Bex and P.M. Midgley (eds.)]. Cambridge University Press, Cambridge, United Kingdom and New York, NY, USA, 1535 pp.

Krishnamurthy PK, Lewis K, Choularton RJ (2014) A methodological framework for rapidly assessing the impacts of climate risk on national-level food security through a vulnerability index. Glob Environ Chang 25:121-132

Kurukulasuriya P, Rosenthal S (2013). Climate Change and Agriculture: A Review of Impacts and Adaptations. Environment department papers;no. 91. Climate change series. World Bank, Washington, DC. https:/openknowledge.worldbank.org/handle/10986/16616

Lewis KH, Lenton TM (2015) Knowledge problems in climate change and security research. WIREs Clim Change 6:383-399. https://doi.org/10.1002/wcc.346

Liu J, Folberth C, Yang H, Rockstrom J, Abbaspour K, Zehnder AJB (2013) A global and spatially explicit assessment of climate change impacts on crop production and consumptive water use. PLoS One 8(2): e57750. https://doi.org/10.1371/journal.pone.0057750

Lobell DB, Burke MB, Tebaldi C, Mastrandrea MD, Falcon WP, Naylor RL (2008) Prioritising climate change adaptation needs for food security in 2030. Science 319(5863):607-610

Lobell DB, Schlenker W, Costa-Roberts J (2011) Climate trends and global crop production since 1980. Science 333(6042):616-620

Nelson GC, Rosegrant MW, Palazzo A, Gray I, Ingersoll C, Robertson R, Tokgoz S, Zhu T, Sulser TB, Ringler C, Msangi S, You L (2010) Food security, farming, and climate change to 2050: scenarios, results, policy options. IFPRI, Washington, D.C

O’Neill B, Kriegler E, Riahi K, Ebi K, Hallegatte S, Carter T, Mathur R, Vuuren D (2014) A new scenario framework for climate change research: the concept of shared socioeconomic pathways. Clim Chang 122(3): $387-400$

OECD (2011) OECD regional typology. OECD, Paris

Parry ML, Rosenzweig C, Iglesias A, Livermore M, Fischer G (2004) Effects of climate change on global food production under SRES emissions and socio-economic scenarios. Glob Environ Chang 14(1):53-67

Porter JR, Xie L, Challinor AJ, Cochrane K, Howden SM, Iqbal MM, Lobell DB, Travasso MI (2014) Food security and food production systems. In: Field CB, Barros VR, Dokken DJ, Mach KJ, Mastrandrea MD, Bilir TE, Chatterjee M, Ebi KL, Estrada YO, Genova RC, Girma B, Kissel ES, Levy AN, MacCracken S, Mastrandrea PR, White LL (eds) Climate change 2014: impacts, adaptation, and vulnerability. Part a: global and sectoral aspects. Contribution of working group II to the fifth assessment report of the intergovernmental panel on climate change. Cambridge University Press, Cambridge and New York, pp 485-533 
Sullivan C (2002) Calculating a water poverty index. World Dev 30:1195-1210

Taylor KE, Stouffer RJ, Meehl GA (2012) An overview of CMIP5 and the experiment design. Bull Amer Meteor Soc 93:485-498

Thompson B, Cohen MJ (2012) The impact of climate change and bioenergy on nutrition. Springer, Dordrecht

Tilman D, Socolow R, Foley JA, Hill J, Larson E, Lynd L, Pacala S, Reilly J, Seachinger T, Somerville C, Williams R (2009) Beneficial biofuels - the food, energy, and environment trilemma. Science 325(5938): 270-271. https://doi.org/10.1126/science.1177970

UNDP (2015) Sustainable Development Goal 2. Available at http://www.undp. org/content/undp/en/home/sdgoverview/post-2015-development-agenda/goal-2.html. Accessed in August 2016

van Vuuren DP, Lucas P, Hilderink H (2007) Downscaling drivers of global environmental change. Enabling use of global SRES scenarios at the national and grid levels. Global Environ Chang 17:114-130

van Vuuren DP, Edmonds J, Kainuma M, Riahi K, Thomson A, Hibbard K, Hurtt GC, Kram T, Krey V, Lamarque J-F, Masui T, Meinhausen M, Nakicenovic N, Smith SJ, Rose SK (2011a) The representative concentration pathways: an overview. Clim Chang 109(1-2):5-31

van Vuuren DP, Stehfest E, den Elzen MGJ, Kram T, van Vliet J, Deetman S, Isaac M, Klein Goldewijk K, Hof A, Mendoza Beltran A, Oostenrijk R, van Ruijven B (2011b) RCP2.6: exploring the possibility to keep global mean temperature increase below $2^{\circ} \mathrm{C}$. Clim Chang 109:95-116. https://doi.org/10.1007/s10584-0110152-3

Vermeulen, S. (2014) Climate change, food security and small-scale producers. Analysis of findings of the Fifth Assessment Reprot (AR5) of the Intergovernmental Panel on Climate Change (IPCC). CCAFS Info Note

Wanders, N., Van Lanen, H. A. J., and van Loon, A. F. (2010) Indicators for drought characterization on a global scale. WATCH Technical Report No. 24

Weedon, G.P., Balsamo, G., Bellouin, N., Gomes, S., Best, M.J. and Viterbo, P., 2014: The WFDEI meteorological forcing data set: WATCH Forcing Data methodology applied to ERA-Interim reanalysis data. Water Resourc Res:50, doi:https://doi.org/10.1002/2014WR015638

Wheeler T, von Braun J (2013) Climate change impacts on global food security. Science 341(6145):508-513 